\title{
QUALITY ASSURANCE GUIDELINES FOR THE ANALYSIS OF SEDIMENT CONCENTRATION \\ BY U.S. GEOLOGICAL SURVEY \\ SEDIMENT LABORATORIES
}

by James M. Knott, Clyde J. Sholar, and Wilbur J. Matthes

U.S. GEOLOGICAL SURVEY

Open-File Report 92-33

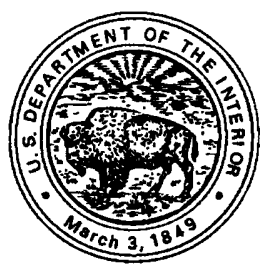

Denver, Colorado

1992 


\section{U.S. DEPARTMENT OF THE INTERIOR \\ MANUEL LUJAN, JR., Secretary}

U.S. GEOLOGICAL SURVEY

Dallas L. Peck, Director

For additional information write to:

Chief, Branch of Quality Assurance U.S. Geological Survey

Box 25046, Mail Stop 401

Federal Center

Denver, CO 80225-0046
Copies of this report can be purchased from:

U.S. Geological Survey Books and Open-File Reports Section Federal Center

Box 25425

Denver, Colorado 80225 


\section{CONTENTS}

Abstract-

Introduction -

Sample integrity-

Sample documentation -

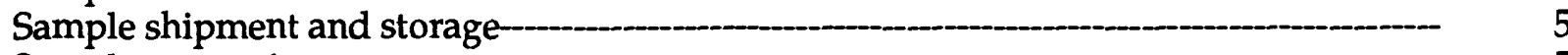

Sample processing - 5

Laboratory equipment 6

Balances - 6

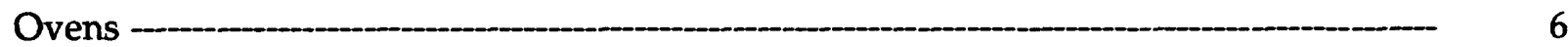

Specific-conductance meters - 6

Decanting equipment - 6

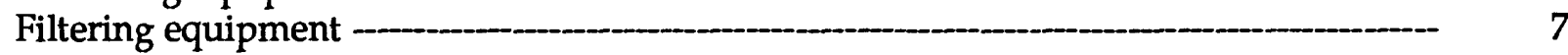

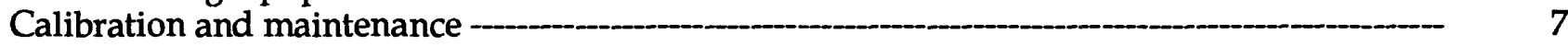

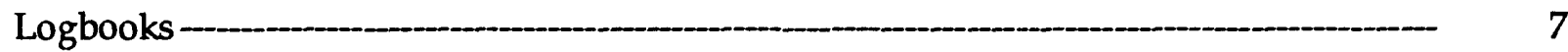

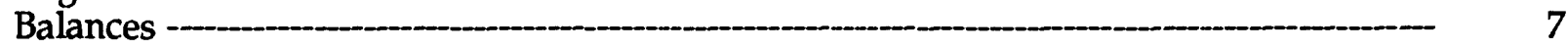

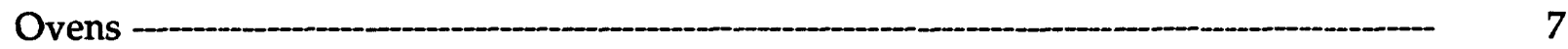

Specific-conductance meters -

Apparatus and standard solutions -

Sample containers/bottles -

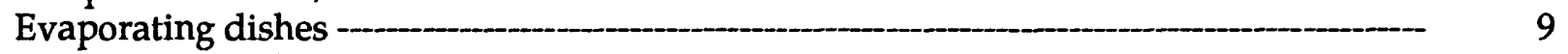

Crucibles and filters -_________ 9

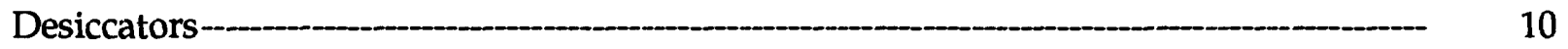

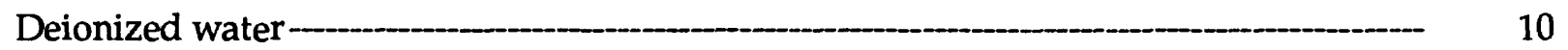

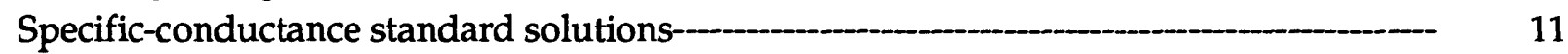

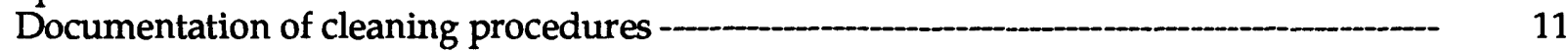

Analytical procedures - 11

Filtration method-_- 12

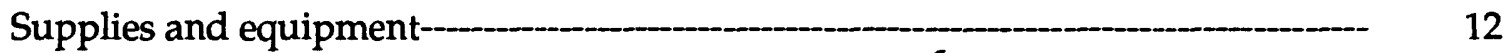

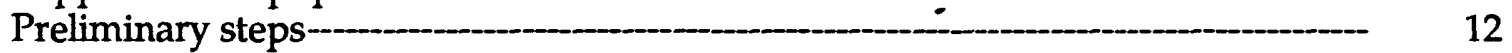

Filtration procedure -._._.

Evaporation method -________ 14

Supplies and equipment-_____- 14

Preliminary steps--_-_._- 14

Dissolved-solids correction procedure-_o

Evaporation procedure -

Conversion of units of concentration -.__

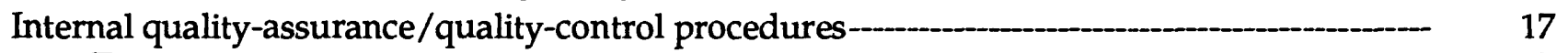

Training - 17

Equipment and standards checks

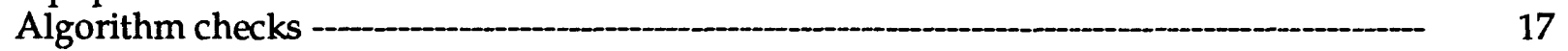

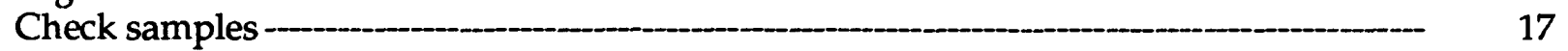

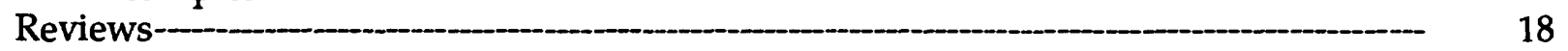

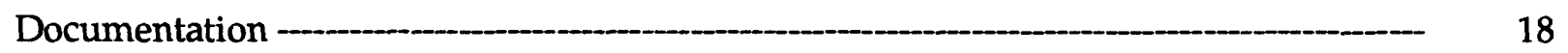

Data security -.._- 18

Glossary - 19

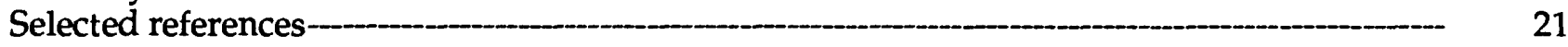

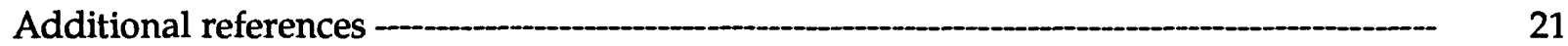




\section{FIGURES}

Figures 1-3. Form for:

Page

1. Sediment-sample field log

2. Sediment-sample shipment log

3. Sediment-concentration notes, depth integrated samples

\section{TABLE}

Table 1. Conversion of units of sediment concentration from parts per million to milligrams per liter

\section{CONVERSION FACTORS AND ABBREVIATED WATER-QUALITY TERMS}

\section{Multiply}

gram (g)

liter (L)

milliliter $(\mathrm{mL})$

millimeter ( $\mathrm{mm}$ )

milligram (mg)

centimeter $(\mathrm{cm})$
By

0.03527

1.057

0.03381

0.03937

35.27

0.3937
To obtain

ounce, avoirdupois

quart, liquid

ounce, fluid

inch

ounce, avoirdupois inch

The following terms and abbreviations also are used in the report:

seconds (s)

liters per second $(\mathrm{L} / \mathrm{s})$

milligrams per liter $(\mathrm{mg} / \mathrm{L})$

hour (h)

grams per liter $(\mathrm{g} / \mathrm{L})$ 


\title{
QUALITY ASSURANCE GUIDELINES FOR THE ANALYSIS OF SEDIMENT CONCENTRATION BY U.S. GEOLOGICAL SURVEY SEDIMENT LABORATORIES
}

\author{
By \\ James M. Knott, Clyde J. Sholar, and Wilbur J. Matthes
}

\begin{abstract}
This report presents quality assurance (QA) and quality control (QC) guidelines for the determination of sediment concentration by U.S. Geological Survey (USGS) sediment laboratories. The guidelines are directed primarily toward the use of acceptable laboratory procedures for the processing and analysis of suspended-sediment samples and the documentation of QA practices.

The report describes procedures for preserving sample integrity, calibrating and maintaining laboratory equipment, cleaning apparatus, analyzing samples, internal QA/QC, and providing data security. The report includes a list of selected references and a glossary of sediment and QA terms.
\end{abstract}

\section{INTRODUCTION}

The Water Resources Division of the USGS currently operates about 25 sediment laboratories in the United States. Most of the laboratories are organized and operated by district offices.

The size and function of USGS sediment laboratories range from facilities that contain limited equipment for simple analysis to laboratories that analyze many sediment samples on a continuous basis or perform a wide variety of complex analyses. The determination of sediment concentration of samples collected from streams is usually considered to be one of the simpler, yet basic analyses performed by USGS sediment laboratories.

Standard procedures developed and used by USGS sediment laboratories on a routine basis are described in Techniques of Water-Resources Investigations of the U.S. Geological Survey, Book 5, Chapter C1 "Laboratory theory and methods for sediment analysis" (Guy, 1969). When this basic laboratory reference was written, however, QA practices in individual laboratories were generally implemented on an informal basis and documentation of the practices was often incomplete.

This report provides guidelines for the establishment of QA/QC practices for the analysis of sediment concentration in USGS sediment laboratories. The guidelines are intended to be applicable to all USGS laboratories, regardless of facility size or function, analyst's experience, or equipment type. Adherence to the guidelines will ensure high, uniform, and well-defined quality analyses and provide adequate documentation of individual QA/QC programs.

This report was compiled in part from material in a $Q A / Q C$ report prepared for a district laboratory (Matthes and others, 1991) and from QA/QC practices used in the California District. The report describes QA practices that have been routinely used in several operating USGS sediment laboratories to ensure the quality of sediment data. The QA practices include techniques and 
procedures applicable to samples, equipment and apparatus, materials, and analyses. The report also includes a list of pertinent references and a glossary of sediment and QA/QC terms.

\section{SAMPLE INTEGRITY}

The quality of sediment data provided by a sediment laboratory is affected by the quality of samples received from the field. Samples received by the laboratory with illegible or incomplete sample-label data, inadequate analysis instructions, or damage may result in erroneous sample documentation, incorrect analytical procedures, or loss of sample integrity.

\section{Sample Documentation}

The amount of information supplied with sediment samples varies acconding to program and processing requirements. The minimum documentation required by the sediment laboratory to process a sample includes:

a. River/stream name and location or station identification number,

b. Date of sample collection,

c. Time of sample collection,

d. Sample type (Equal Width Increment, Equal Discharge Increment),

e. Requested type of analysis, and

f. Customer identification.

Sample documentation includes written information on both the sample containers and the field forms. Examples of pertinent sampling information are shown in Guy and Norman (1970, p. 29 and 48) and in Edwards and Glysson (1988, p. 52 and 83). Some sediment-sampling programs may require additional information to ensure samples will be adequate for data requirements.

Sample documentation that assists the laboratory in organizing and analyzing the samples includes the use of field and shipment logs (Matthes and others, 1991). The field log (fig. 1) is prepared by the person responsible for operating a sampling station. The log includes information pertaining to samples collected by observers, by pumping samplers, and by USGS personnel. A field log accompanies each case of sample containers and is generally in a zip-lock plastic bag to protect the log from damage.

A shipment log form (fig. 2) is used when shipping the samples to the sediment laboratory. This form contains information to assist laboratory personnel in the sorting of samples for analysis. The shipment log is generally sent to the laboratory under separate cover when the samples are shipped to verify that the entire shipment has been received and to ensure that the field information is available when the shipment arrives.

The minimum QA/QC requirements for sample documentation are as follows:

a. Written information on sample containers is examined for legibility and for completeness.

b. Field and shipment logs are examined by the laboratory to assure that information required for analysis is complete.

c. A record is kept of sample-document examinations by the laboratory, which includes station name, examination dates, comments pertinent to sample documentation, and correspondence regarding customer notification of deficiencies. 
STATION NUMBER

CURRENT DATE

CASE NUMBER

CAN CAPS BE READ? Yes of
RIVER NAME

INITIALS OFFICE

CONDITION OF SAMPLES?

ARE BOTTLES IN ORDER? Yes No

REMARKS:

DID YOU TALK TO OBSERVER? Yes No
TYPE OF ANALYSIS:
1) CONCENTRATION ONLY
2) COMPOSITE CONCENTRATION
3) SAND / FINE BREAK
4) COMPOSITE SAND / FINE BREAK
5) PARTICLE SIZE
6) COMPOSITE PARTICLE SIZE

7) OTHER - EXPLAIN IN REMARKS

\begin{tabular}{|c|c|c|c|c|c|c|c|}
\hline $\begin{array}{l}\text { BOTTLE } \\
\text { NUMBER }\end{array}$ & $\begin{array}{c}\text { SAMPLE } \\
\text { DATE }\end{array}$ & $\begin{array}{l}\text { ANALYSIS } \\
\text { REQUIRED }\end{array}$ & REMARKS & $\begin{array}{l}\text { BOTTLE } \\
\text { NUMBER }\end{array}$ & $\begin{array}{c}\text { SAMPLE } \\
\text { DATE }\end{array}$ & $\begin{array}{l}\text { ANALYSIS } \\
\text { REQUIRED }\end{array}$ & REMARKS \\
\hline 1 & & & & 15 & & & \\
\hline 2 & & & & 16 & & & \\
\hline 3 & & & & 17 & & & \\
\hline 4 & & & & 18 & & & \\
\hline 5 & & & & 19 & & & \\
\hline 6 & & & & 20 & & & \\
\hline 7 & & & & 21 & & & \\
\hline 8 & & & & 22 & & & \\
\hline 9 & & & & 23 & & & \\
\hline 10 & & & & 24 & & & \\
\hline 11 & & & & 25 & & & \\
\hline 12 & & & & 26 & & & \\
\hline 13 & & & & 27 & & & \\
\hline 14 & & & & 28 & & & \\
\hline
\end{tabular}

TOTAL \# OF OBS. SAMPLES

TECHNICIAN SAMPLES FROM FIXED LOCATION

X-SECTION

START NEW LOG FORM FOR EACH CHANGE OF RIVER, OR CHANGE OF SAMPLE MODE. KEEP FORM(S) IN CASE WITH SAMPLES

Figure 1.-Form for sediment-sample field log. 
DATE OF SHIPMENT

CASE/BOX NUMBER

STATION NAME

TYPE OF SAMPLE: DAILY, EWI, EDI, OTHER COMPOSITE FOR ANALYSIS: YES, NO.

TYPE OF ANALYSIS: CONCENTRATION ONLY, SAND/FINE BREAK COMPLETE SIZE.

BEGIN DATE END DATE
DATE RECEIVED

STATION NUMBER

REMARKS:

(Circle appropriate response)

DATE OF SHIPMENT

CASE/BOX NUMBER

STATION NAME

TYPE OF SAMPLE: DAILY, EWI, EDI, OTHER COMPOSITE FOR ANALYSIS: YES, NO.

TYPE OF ANALYSIS: CONCENTRATION ONLY, SAND/FINE BREAK COMPLETE SIZE.

BEGIN DATE END DATE

REMARKS:

(Circle appropriate response)

DATE OF SHIPMENT

CASE/BOX NUMBER

STATION NAME

TYPE OF SAMPLE: DAILY, EWI, EDI, OTHER COMPOSITE FOR ANALYSIS: YES, NO.

TYPE OF ANALYSIS: CONCENTRATION ONLY, SAND/FINE BREAK COMPLETE SIZE.

BEGIN DATE

END DATE
DATE RECEIVED

STATION NUMBER

REMARKS:

(Circle appropriate response)

Figure 2.--Form for sediment-sample shipment log. 


\section{Sample Shipment and Storage}

The use of improper procedures in the shipment and storage of sediment samples may affect the validity of the sample analysis. If samples are not properly shipped, sample integrity may be compromised by contamination, loss of contents, or physical or chemical alteration. Proper storage, in a cool, dark place, decreases the rate of organic growth and evaporation within the sample bottle.

Sample shipment during warm periods generally results in few problems. Sample shipment during cold periods, however, can result in sample or container damage due to freezing. Freezing can cause dissolved solids to precipitate and can cause container breakage or leakage. During cold periods, samples are shipped in heated vehicles. Insulated containers may be used for overnight shipment, if temperatures are not extremely low.

Each laboratory needs to have a written information sheet that summarizes laboratory policy for sample shipment and storage. Instructions for shipment and storage of samples are given to each customer. Sample storage instructions are to be displayed in the sample storage room.

\section{Sample Processing}

Upon receipt at the laboratory, samples and forms included in shipping containers should first be examined for sample condition and requested analysis type. Loose container caps are replaced and containers with dirty exteriors are cleaned. A sample in a damaged container is discarded unless the sample can be reconstituted. It may be possible to transfer the sample to a new container or to determine the amount of water/sediment loss. Pertinent comments regarding sample condition are recorded on a log-in form or on shipping forms. The customers are promptly notified of sample deficiencies.

Shipping containers can be tagged and dated upon arrival at the laboratory. The tags might be color-coded to indicate the month samples were received.

If possible, sediment samples are analyzed within 60 days after they are received at the laboratory. If a sample cannot be analyzed within the required period, the sample mass is determined within a week and recorded to avoid errors due to evaporation.

Minimum $Q A / Q C$ requirements for sample processing are documentation of the following:
a. Examination of field and shipping forms,
b. Examination of sample-container integrity,
c. Completion of sample log-in forms,
d. Weekly inspections of date-coded or color-coded tags on shipping containers, and
e. Maintenance of a filing system for laboratory log-in forms and field-supplied information.

Samples are generally transferred to a weighing station within one week, but not exceeding two weeks, of their arrival at the laboratory. At the weighing station, a unique sample identification number, sample information, and pertinent log-in data may be recorded on a log-in form or in a computer file. During or shortly following the log-in operation, the samples can be sorted by station and arranged chronologically so that the sample with the oldest sampling time is first to be analyzed. Samples can be separated into groups according to the required type of analysis. 


\section{LABORATORY EQUIPMENT}

The weighing, processing, and analysis of samples for sediment concentration require the use of a variety of specialized equipment. Some of the equipment, such as balances, ovens, specificconductance meters, vacuum pumps, thermometers, and calculators can be obtained from commercial sources. Other equipment, such as decanting or filtering devices, must be assembled or fabricated.

\section{Balances}

Two types of balances, macro and analytical, are required for the weighing of sediment samples and containers. The balance specifications are important because of the specific uses of the balances in the laboratory.

The macro balance is used to determine the tare mass of sample containers and sample mass (water plus sediment). The macro balance should be capable of determining masses ranging from about 100 to $3,000 \mathrm{~g}$ within plus or minus $0.5 \mathrm{~g}$.

The analytical balance is used for the weighing of dry sediment, crucibles, evaporating dishes, and other apparatus whose mass is less than about $200 \mathrm{~g}$. The analytical balance should have a required precision of $0.0005 \mathrm{~g}$.

\section{Ovens}

Convection-type ovens are used to dry the sediment samples and various types of laboratory apparatus. The ovens are normally operated at temperatures ranging from 80 to $110^{\circ} \mathrm{C}$. The oven should be able to maintain a temperature within plus or minus two degrees Celsius of the indicated oven setting.

\section{Specific-Conductance Meters}

Specific conductance of a water-sediment mixture is often a useful indicator of the conductivity of a stream at the time a sample was collected. Specific-conductance meters are generally used in the laboratory to assure the quality of samples collected at field sites and the purity of deionized water used in the laboratory. The meter should be capable of readings as low as $1.0 \mu \mathrm{S} / \mathrm{cm}$. Accuracy of the meter should be within 5 percent for a range of $10-100 \mu \mathrm{S} / \mathrm{cm}$ and within 2 percent for conductivities exceeding $100 \mu \mathrm{S} / \mathrm{cm}$.

\section{Deconting Equipment}

Decanting equipment generally consists of a J-shaped decanting nozzle attached to rubber or plastic tubing and connected to a vacuum system. The nozzle is inserted into the sample container prior to analysis. It is used to decrease most of the water part of the water-sediment mixture without removing any of the sediment. Decanting vacuum can be obtained by the use of low-capacity (about $7-15 \mathrm{~L} / \mathrm{s}$ ) aspirator or vacuum pumps. 


\section{Filtering Equipment}

Filtering equipment is used in the filtration-method analysis of sediment samples. The equipment generally consists of a crucible holder (with filter adapter and glass funnel stem), tubing, shut- off valve, surplus water collector, and a vacuum device. Several crucible holders are generally grouped together and supported by a rigid structure called a filtration rack.

\section{CALIBRATION AND MAINTENANCE}

Calibrated equipment is essential to the achievement of reliable analytical results. A laboratory should maintain the calibration of its equipment by systematic checking against reference standards and by adequate maintenance schedules. Documentation of equipment calibration, checking, and maintenance is essential to support the quality assurance program of a given laboratory. Calibration records are to be recorded in a logbook that is stored in the laboratory.

\section{Logbooks}

A logbook is kept for recording calibration and maintenance for each balance, conductivity meter, oven, and oven thermometer. The date and analyst's initials are the first items to be recorded for each log entry. The date and analyst's initials are followed by the required entry and comments for each instrument, meter, or item of equipment.

Minimum requirements for calibration, checking, and maintenance are documented for each sediment laboratory. These requirements may consist of manufacturers' recommendations or specific requirements for an individual laboratory.

\section{Balances}

Balances are mounted on a heavy shock-proof table. Balances should not be subject to vibrations or excessive changes in humidity or temperature.

Each day, prior to use, the analyst should check the balances. Macro and analytical balances will be checked with at least two Class S weights, traceable to the National Institute of Standards Technology. The sizes of the standard weights are representative of the range in mass of the items to be weighed. The balances must be recalibrated if the error between the balance and the standard weights exceeds $0.5 \mathrm{~g}$ (macro balance) or $0.001 \mathrm{~g}$ (analytical balance). The balances are readjusted to zero after each 10 weighings.

The balance must be serviced and calibrated by a manufacturer's representative if laboratory personnel cannot achieve recalibration within required tolerances. All balances are serviced and calibrated by a manufacturer's representative at least once a year. All balance checks, calibrations, and professional servicing will be recorded in the instrument logbook. A separate logbook is maintained for each balance.

\section{Ovens}

Thermometers used in drying ovens are checked at least once a month when in use. The thermometer should be checked at 80 and $110^{\circ} \mathrm{C}$ against a thermometer of known calibration 
accuracy $\left( \pm 0.1^{\circ} \mathrm{C}\right)$. An oven thermometer is replaced if its indicated temperature differs by more than $\pm 2.0^{\circ} \mathrm{C}$ compared to the calibrated thermometer.

Oven temperature is read twice daily during operation and recorded in a logbook. A separate logbook is used to record daily temperature readings and monthly thermometer checks for each oven.

\section{Specific-Conductance Meters}

Each week prior to use, the specific-conductance meter is checked for linearity with at least three standards representative of anticipated sample conductance. The specific-conductance meter is checked daily with at least two standards representative of anticipated sample conductance. If the meter varies by more than \pm 2.0 percent from any one of the standards, it is checked with a standard of comparable conductance. If it is determined that the meter is in error, the probe is cleaned following manufacturer-suggested procedures or replaced.

Calibration and maintenance of laboratory equipment are important parts of the laboratory QA/QC. Each item of equipment (balances, ovens, and meters) needs to have scheduled maintenance. The maintenance schedules are documented in the appropriate logbooks. Logbook data are evaluated periodically to determine if equipment condition or performance is gradually deteriorating.

\section{APPARATUS AND STANDARD SOLUTIONS}

Laboratory apparatus includes a variety of containers, glassware, and supplementary items that are commonly used in the analysis of suspended-sediment concentration. This section includes a brief description of the apparatus and a discussion of special cleaning, preparation, and/or maintenance procedures.

\section{Sample Containers/Bottles}

Standard suspended-sediment samplers, used by the USGS, accommodate different sample container sizes and types (Edwards and Glysson, 1988). The most common types of sample container include the standard pint-sized glass milk bottle (used by many American and Canadian milk companies prior to 1970), quart-sized glass mayonnaise bottles, and 1/2 liter-, liter-, quart-, or 3-liter-sized plastic bottles.

Tare mass of the empty containers should be determined to the nearest $1 \mathrm{~g}$ and permanently marked on the containers prior to the collection of sediment samples. Container tare mass should be obtained minus labels, tags, or container caps. Glass bottles are tared by use of a fine-tipped engraving tool. Paint or a permanent waterproof marker is adequate for taring plastic containers.

Sample containers should be inspected prior to washing. If the containers contain a precipitate or residue, they should be rinsed in a 5 to 15 percent hydrochloric-acid $(\mathrm{HCl})$ solution. It is important to wear adequate protective gloves, clothing, and goggles when using acid to pre-clean sample bottles.

Glass sample containers can be washed with a laboratory detergent. Soaking or scrubbing may be required to remove writing from the containers. A thonough rinse in tap water will remove 
detergent residue. After drying, containers should be inspected for cleanliness and physical damage.

Sample containers should be closely inspected for chips, cracks, abrasions, or holes. Chipped glass containers should be retared. Containers with damage that may result in possible leakage or sample loss should be discarded.

Plastic sample containers, depending on shape or style, are usually more difficult to clean than glass. Most plastic containers are opaque and residues are difficult to see. If a buildup is observed, rinse with a 5 to 15 percent $\mathrm{HCl}$ solution, wash with detergent, and gently brush the interior by hand. Do not use a machine brush as many plastics can be scratched, and part of subsequent sediment samples may become embedded in the scratch marks. Plastic containers should be thoroughly rinsed in tap water to remove detergent residue, dried, and inspected.

Five percent of each group of clean dry containers are reweighed to confirm indicated tare masses. If the mass of any container exceeds the mass indicated on the container by more than plus or minus one gram, an additional five percent of the group are reweighed. If the tare mass of any of these containers exceeds the allowable error, all containers in the group are retared.

Masses of sample container labels, tags, and caps are generally a small percentage of sample or container masses. Average masses of these items, however, can be determined for each type of sample container and recorded for adjustment of container tare mass.

\section{Evaporating Dishes}

Evaporating dishes are typically made of high thermal glass with a lip for pouring. A capacity of $100 \mathrm{~mL}$ is required to hold normal decanted volumes of $20-70 \mathrm{~mL}$. The dishes are numbered by the use of an engraving tool or high-temperature paint.

The dishes are cleaned by hand-washing in laboratory detergent. Scrubbing may be needed to remove precipitates or detergent residue. Rinsing in tap water and air drying are usually adequate to obtain clean dishes. The dishes are stored in closed compartments or drawers that are not susceptible to moisture or dust accumulation.

The tare masses of evaporating dishes are determined within $0.0001 \mathrm{~g}$ prior to use. If laboratory humidity is high, it may be necessary to store the dishes in a desiccator jar prior to taring.

\section{Crucibles and Filters}

Gooch ${ }^{1}$ porcelain or glass crucibles are commonly used in USGS sediment laboratories for the filtration of sediment samples (filtration method). The porcelain crucible has a perforated bottom and a capacity of about $25 \mathrm{~mL}$. The glass crucible has a fritted-glass dish which can be removed. Both crucibles are used with a disposable glass-fiber filter.

Crucibles are hand-washed in laboratory detergent and rinsed with tap water to remove detergent residue. Crucibles with fritted-glass discs require periodic cleaning in an ultrasonic cleaner. Cleaning time varies according to the power rating of the cleaner and the type of sediment.

${ }^{1}$ The use of trade or product names is for identification purposes only and does not constitute endorsement by the U.S. Geological Survey. 
Ultrasound cleaning is required if the filtering time exceeds 30 seconds. Treatment with a 5- to 15-percent $\mathrm{HCl}$ solution may be needed for sediment-residule removal. Crucibles should be stored in desiccator jars after they have been washed and air-dried.

Gooch crucible filters should conform to Whatman glass-fiber filter No. 934-AH or equivalent filter type. Filters should be seated on the bottom of a clean crucible, wetted with distilled or deionized water, and placed under vacuum. The vacuum pulls the filter down flush with the bottom of the crucible and forms a tight seal. If the filter is not seated properly, air may escape around the filter and result in a hissing-like sound. The filter may need to be adjusted or replaced in order to obtain a proper seal.

After the filters are properly seated, the crucibles should be placed on a metal tray and dried in a convection oven set at $105^{\circ} \mathrm{C}$. After drying for 2 hours, remove the hot crucibles and place them into desiccator jars. Crucibles should be stored in the desiccator jar for at least 8 hours before taring. Tare mass of the crucible (with filter) to within $0.0001 \mathrm{~g}$ prior to filtration of the water-sediment mixture.

\section{Desiccators}

Desiccators are used to store the crucibles and evaporating dishes after their removal from the drying oven. Desiccator storage prevents the absorption of moisture by the sample prior to final weighing of the dry sediment.

The desiccator should be inspected prior to each use to ensure that the seal between the jar and the lid is airtight and that moisture accumulation in the desiccant is not excessive. During each inspection, old desiccator grease should be wiped off, and a small amount of new grease should be applied to the contact surfaces of the jar and lid.

Desiccant with a color indicator indicates moisture accumulation by a change in color. The desiccant can be reused by drying in an oven until the original color is restored.

Desiccant should be replaced at 6-month intervals or whenever the color of the desiccant approaches the color indicated in the manufacturer's instructions. The desiccant should be removed from the desiccator and thoroughly dried in an oven. Old sealant grease should be removed, and the desiccator should be cleaned with a laboratory detergent. After recharging the desiccator with desiccant and application of new grease, the date of cleaning should be marked on each desiccator and documented in a logbook.

\section{Deionized Water}

Deionized and distilled (DI) water is used in the laboratory to seat filters in crucibles and to wash samples into crucibles, evaporating dishes, and other containers. It is also used for some laboratory cleaning procedures to prevent the accumulation of dissolved solids.

DI water is generally obtained by passage through a mixed cation-anion exchange resin or distillation. All DI water, used in a sediment laboratory, is filtered through a 0.45 micron membrane filter. If the DI water is prepared by the laboratory, manufacturer's instructions should be followed. Specific conductance of the DI water must not exceed $10 \mu \mathrm{S} / \mathrm{cm}$.

The specific conductance of each new batch of DI water will be determined and recorded in a logbook. Specific conductance of stored water will be checked and recorded. 
Storage containers for DI water will need occasional cleaning with DI water and liquid bleach to remove accumulations of organic material. Small portable storage containers can be cleaned as follows:

1. Add a mixture of water and liquid bleach to the container (the mixture contains about $250 \mathrm{~mL}$ of bleach to 20 liters of water).

2. Agitate the solution and soak the container for 5 minutes.

3. Repeat the agitation and soaking procedure at least three times.

4. A brush can be used to remove deposited materials.

5. Rinse the container several times with DI water to remove the bleach residue.

\section{Specific-Conductance Standard Solutions}

Specific-conductance standards may be obtained from the USGS National Laboratory in Denver, Colorado, the USGS Laboratory in Ocala, Florida, and from commercial suppliers. All standards must be labeled with an expiration date and should not be used after that date.

Specific-conductance standards should be stored in tightly capped containers to avoid contamination and evaporation. Extreme care should always be taken to avoid contamination. The portion of a standard used for calibration must always be discarded, and no standard is to be returned to the original container.

\section{Documentation of Cleaning Procedures}

Written cleaning procedures for sample containers, evaporating dishes, and crucibles should be read and readily available to laboratory personnel. These procedures should be posted or stored near the cleaning area. Logbooks used to document the taring of sample bottles, evaporating dishes, and crucibles should be examined at least once a month by the laboratory supervisor. Records of the desiccator cleaning, desiccant changes, and deionized water testing should be recorded and reviewed at least once every 6 months. The laboratory supervisor is responsible for determining whether proper $\mathrm{QA} / \mathrm{QC}$ procedures were followed.

\section{ANALYTICAL PROCEDURES}

The method used in USGS sediment laboratories to determine the concentration of sediment in water samples are those described in Book 5, Chapter $\mathrm{Cl}$ of the series "Techniques of WaterResources Investigations of the United States Geological Survey."

Sediment concentration, as analyzed by USGS sediment laboratories, consists of the ratio of the mass of dry sediment in a water-sediment mixture to the mass of the mixture. The ratio is multiplied by 1 million to obtain an initial concentration expressed in parts per million (eq. 1, "Filtration Procedure").

Two methods, filtration and evaporation, may be used to determine sediment concentration. The filtration method generally uses a crucible with perforated bottom, crucible filter, filtering equipment, and vacuum system. The sample is poured into the crucible, filtered, dried, and weighed. The primary advantages of this method are that dissolved solids present in the watersediment mixture will pass through the filter and that a short analysis time is used if the amount of sediment is small. 
The evaporation method is generally preferred if the concentration of the water-sediment mixture exceeds about $10,000 \mathrm{mg} / \mathrm{L}$ of sediment that is mostly clay (less than $0.004 \mathrm{~mm}$ ) according to Guy (1969). The evaporation method uses an evaporation dish to contain the sediment. After washing the water-sediment mixture into the evaporation dish, the sample is dried and weighed. The primary disadvantage of the evaporation method is that a correction for dissolved solids may be required. Guy $(1969$, p. 12) provides guidelines for determining whether or not a dissolved-solids correction is needed.

\section{Filtration Method \\ Supplies and Equipment}

1. Concentration analysis forms (fig. 3).

2. Gooch crucibles with perforated bottom, size \# 4, porcelain or clear glass with fritted disk.

3. Gooch crucible holder, Walter, $38 \mathrm{~mm}$ at top, $22 \mathrm{~mm}$ at bottom.

4. Filter paper, glass fiber, Whatman $934 \mathrm{AH}$ or similar, $2.4 \mathrm{~cm}$ or appropriate diameter.

5. One liter flask, filtering, Pyrex (\#8 stopper). An alternate filtering rack-apparatus can be designed for filtering about eight crucibles.

6. Vacuum device.

7. Standard laboratory equipment (analytical and macro balance, drying oven, desiccator jar, decanting equipment, plastic washing bottle, plastic or rubber tubing).

\section{Preliminary Steps}

1. Record appropriate field-sampling information on concentration-analysis form.

2. Determine the mass of the water-sediment mixture to the nearest $1 \mathrm{~g}$ and record on analysis form.

3. Insert a crucible filter into a crucible. Seat the filter by placing the crucible in a filtering rack, applying vacuum, and wetting the filter with DI water. Listen for a hissing sound. This may occur if the filter paper is not seated properly or is defective. Replace filter paper, if needed.

4. Dry crucible (with filter) in the oven for at least 1 hour at $105^{\circ} \mathrm{C}$ and cool at least 3 hours or overnight in a desiccator jar.

5. Determine the mass of the crucible (with filter) to the nearest $0.0001 \mathrm{~g}$ and record tare value and crucible number on the analysis form.

6. Crucibles should be replaced in the desiccator if they are not to be used within a few hours. Crucibles should never be moved with bare fingers. Tongs, plastic gloves, rubber fingertips, or similar items must be used in order to avoid deposits of moisture, dirt, or oil on the crucible.

\section{Filtration Procedure}

1. Decant most of the sediment-free water from the sample container, using care not to disturb or remove sediment from the container. 


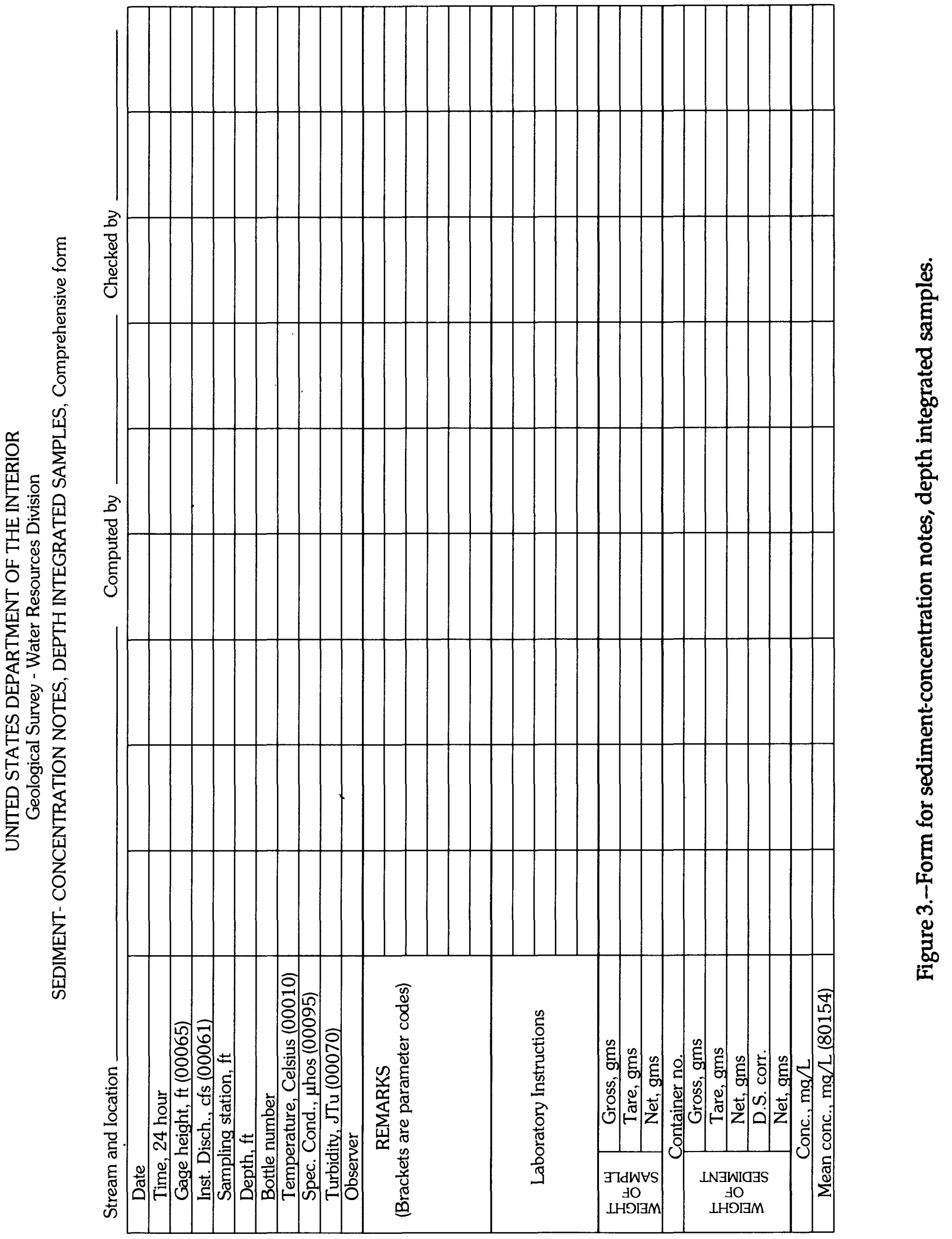


2. Wash the remaining water-sediment mixture into a crucible (with filter) under vacuum. DI water should be used for the washing.

3. Dry the crucible and retained sediment at $95^{\circ} \mathrm{C}$ until visible moisture has evaporated. The crucible, filter, and retained sediment may be dried in the oven over night at 85 to $95^{\circ} \mathrm{C}$. Raise the temperature of the oven to $105^{\circ} \mathrm{C}$ and dry crucible for one hour. After drying, cool the crucible in a desiccator jar for at least 3 hours or overnight.

4. Determine the gross mass of the crucible and sediment and record the gross value on the analysis form.

5. Determine the net mass of the dry sediment and record on the analysis form.

6. Calculate the concentration in PPM.

$$
\text { Concentration in PPM }=\frac{\text { dry sediment mass }}{\text { water-sediment mass }} \times 1,000,000
$$

\section{Evaporation Method}

\section{Supplies and Equipment}

1. Concentration analysis forms.

2. Evaporating dishes ( 80 and $105 \mathrm{~mm}$ ).

3. Pipette ( $25 \mathrm{~mL})$.

4. Standard laboratory equipment (item 7 in the "Supplies and Equipment" section, "Filtration Method").

\section{Preliminary Steps}

1. Record appropriate field-sampling information on analysis form.

2. Determine the mass of the water-sediment mixture to the nearest $1 \mathrm{~g}$ and record on analysis form.

3. Determine the approximate dissolved-solids correction factor for 20 to $50 \mathrm{~mL}$ of native water. This correction factor can be determined using one of the following methods.

a. The specific conductance of the sample can be measured. According to Hem, 1970, p. 99, the ratio of dissolved-solids concentration $(\mathrm{mg} / \mathrm{L})$ to specific conductance $(\mu \mathrm{S} / \mathrm{cm})$ ranges from 0.55 to 0.75 .

b. Aliquots for several samples obtained during low flows can be composited and analyzed for dissolved solids. The results will usually indicate whether a correction is needed. Refer to Guy, 1969, p. 12 and 17 and figure 3.

c. Determine the dissolved-solids correction for the sample. Refer to the dissolved-solids correction procedure that follows this section of the report. 
4. Determine the mass of a clean evaporating dish to the nearest $0.0001 \mathrm{~g}$ and record the tare mass and dish number on the analysis form.

5. Evaporating dishes should never be moved with bare fingers.

\section{Dissolved-Solids Correction Procedure}

1. Determine the tare mass of the evaporating dish $(80 \mathrm{~mm})$ and record the tare result on the analysis form.

2. Take a 25-mL pipette sample of the native water (sediment-free) and empty into the evaporating dish (item 1 ).

3. Dry the evaporating dish $\left(85\right.$ to $\left.95^{\circ} \mathrm{C}\right)$ until the visible moisture has evaporated. Raise the oven temperature to $105^{\circ} \mathrm{C}$ for 1 hour and cool the evaporating dish in a desiccator jar.

4. Determine the gross mass of the evaporating dish and solid residue and record the gross value on the analysis form.

5. Determine the net mass of the residue and record on the analysis form.

6. Compute the dissolved-solids correction. The correction (c) is equal to:

$$
C=\frac{\text { net mass of residue } x \text { sample volume (after decanting) }}{25 \mathrm{~mL} \text { (pipette volume) }}
$$

The mass is measured to the nearest $1 \mathrm{~g}$, or the volume of sample (after decanting) is estimated to the nearest $1 \mathrm{~mL}$.

\section{Evaporation Procedure}

1. Decant most of the sediment-free water from the sample container, using care not to disturb or remove sediment. Not more than 20 to $50 \mathrm{~mL}$ of native water should remain in the sample container.

2. Wash the remaining water-sediment mixture into the evaporating dish. DI water is used for the washing.

3. Dry the sample in the oven at $85-95^{\circ} \mathrm{C}$ until visible moisture has evaporated. Raise the oven temperature to $105^{\circ} \mathrm{C}$ for 1 hour. After drying, cool the evaporating dish in a desiccator jar for at least 3 hours.

4. Determine the gross mass of the dish and sediment to the nearest $0.0001 \mathrm{~g}$ and record the gross value on the analysis form.

5. Determine the net mass of the dry sediment and record on the analysis form (Subtract the dissolved-solids correction, if needed.).

6. Calculate the concentration, in PPM (computation description in "Filtration Procedure" section).

\section{Conversion of Units of Concentration}

Sediment-concentration analyses are initially computed in parts per million. The current USGS policy, however, is to publish sediment concentration in $\mathrm{mg} / \mathrm{L}$ rather than in PPM. The conversion of PPM to $\mathrm{mg} / \mathrm{L}$ is made using table 1. 
Table 1.--Conversion of units of sediment concentration from parts per million to milligrams per liter

[The concentration, in milligrams per liter, is obtained by multiplying the concentration, in parts per million (PPM), by the coefficient (C). The factors are based on the assumptions that the density of water is 1.000 , plus or minus 0.005 , the range of temperature is $0-20^{\circ} \mathrm{C}$, the specific gravity of sediment is 2.65 , and the dissolved solids concentration is less than 10,000 PPM]

\begin{tabular}{|c|c|c|c|}
\hline $\begin{array}{r}\text { Concentration } \\
\text { range (PPM) }\end{array}$ & $\begin{array}{c}\text { Coefficient } \\
\text { C }\end{array}$ & $\begin{array}{l}\text { Concentration } \\
\text { range (PPM) }\end{array}$ & $\begin{array}{c}\text { Coefficient } \\
\text { C }\end{array}$ \\
\hline $0-\quad 7,990$ & 1.00 & $327,000-336,000$ & 1.26 \\
\hline $8,000-23,700$ & 1.01 & $337,000-346,000$ & 1.27 \\
\hline $23,800-39,200$ & 1.02 & $347,000-356,000$ & 1.28 \\
\hline $39,300-54,300$ & 1.03 & $357,000-366,000$ & 1.29 \\
\hline $54,400-68,200$ & 1.04 & $367,000-375,000$ & 1.30 \\
\hline $69,300-83,700$ & 1.05 & $376,000-385,000$ & 1.31 \\
\hline $83,800-98,000$ & 1.06 & $386,000-394,000$ & 1.32 \\
\hline $98,100-112,000$ & 1.07 & $395,000-403,000$ & 1.33 \\
\hline $113,000-126,000$ & 1.08 & $404,000-412,000$ & 1.34 \\
\hline $127,000-139,000$ & 1.09 & $413,000-421,000$ & 1.35 \\
\hline $140,000-153,000$ & 1.10 & $422,000-429,000$ & 1.36 \\
\hline $154,000-166,000$ & 1.11 & $430,000-438,000$ & 1.37 \\
\hline $167,000-178,000$ & 1.12 & $439,000-446,000$ & 1.38 \\
\hline $179,000-191,000$ & 1.13 & $447,000-455,000$ & 1.39 \\
\hline $192,000-203,000$ & 1.14 & $456,000-463,000$ & 1.40 \\
\hline $204,000-215,000$ & 1.15 & $464,000-471,000$ & 1.41 \\
\hline $216,000-227,000$ & 1.16 & $472,000-477,000$ & 1.42 \\
\hline $228,000-239,000$ & 1.17 & $480,000-487,000$ & 1.43 \\
\hline $240,000-251,000$ & 1.18 & $488,000-495,000$ & 1.44 \\
\hline $252,000-262,000$ & 1.19 & $496,000-502,000$ & 1.45 \\
\hline $263,000-273,000$ & 1.20 & $503,000-510,000$ & 1.46 \\
\hline $274,000-284,000$ & 1.21 & $511,000-517,000$ & 1.47 \\
\hline $285,000-295,000$ & 1.22 & $518,000-525,000$ & 1.48 \\
\hline $296,000-306,000$ & 1.23 & $526,000-532,000$ & 1.49 \\
\hline $307,000-316,000$ & 1.24 & $533,000-539,000$ & 1.50 \\
\hline $317,000-326,000$ & 1.25 & & \\
\hline
\end{tabular}




\section{INTERNAL QUALITY ASSURANCE/QUALITY CONTROL PROCEDURES}

Internal QA/QC procedures provide a means to define the quality of the data and to alert the analyst and responsible administrators to needed changes in laboratory operations. Internal QA/QC procedures include training, equipment and standards checks, algorithm checks, analysis of check samples, and reviews.

\section{Training}

All laboratory personnel should participate in training and proficiency test programs for each type of analysis they are expected to make. The period of training will vary depending on the complexity of analysis. A record of individual analyst training, test results, and review comments should be maintained.

\section{Equipment and Standards Checks}

A logbook should be maintained for each balance, meter, and oven as discussed in the "CALIBRATION AND MAINTENANCE" section. A logbook should also be maintained to record information pertinent to maintenance of apparatus and checking of DI water and standard reagents.

\section{Algorithm Checks}

Calculators and computer algorithms should be checked periodically. Examples of analyses with known input values and results can be used to verify that computations are correct.

\section{Check Samples}

Quality control samples should account for at least 5 percent of the samples analyzed by the laboratory. The QC program includes replicate, reference, and blank samples that are inserted into the normal sample flow.

Blank samples, prepared from DI water, will constitute about 50 to 80 percent of the QC samples. The analyst should mark these samples clearly and insert them uniformly throughout each sample group.

Reference and replicate samples are more effectively used when they are inserted as "blind" samples. At present, most of these samples are supplied by field personnel or laboratory supervisors. The USGS is currently working with the American Society for Testing and Materials to develop standard reference samples, and these samples will be supplied when they are available.

Logbooks are maintained for analyses of QC samples. Failure to obtain the expected results on any QC analysis will require immediate action to identify, correct, and document the problem. Records of corrective actions are included in the logbooks. 


\section{Reviews}

The analyst computes, initials, and dates all analysis results. The analyst is responsible for reviewing the analyses for completeness and reasonableness. The laboratory supervisor or a person responsible for $Q A$ activities will review analyses of the $Q C$ samples. Notes on corrective actions are included in the QA/QC logbook and in appropriate files.

\section{Documentation}

Documents required to support the $Q A / Q C$ program of a sediment laboratory include basic references, a procedures manual, logbooks, and laboratory documents and correspondence.

1. Basic references should include Book 5 , Chapters $A 1$ and $C 5$ of the TWRI series, a recent copy of the Annual Book of ASTM Standards (available from ASTM, Philadelphia, PA), containing standards D1889-85 and D3977-80, and appropriate internal memoranda of the Water Resources Division and the Division's Office of Surface Water and Office of Water Quality.

2. A procedures manual should be available that describes the specific methods, procedures, instruments, and equipment that are used by the laboratory. The manual should be updated periodically to document changes in equipment, apparatus, or facilities. Changes or modifications to methods of analysis should be made only after notification to and approval by the Office of Surface Water.

3. Logbooks are required to provide documentation of equipment calibration and maintenance, analysis of $\mathrm{QA} / \mathrm{QC}$ samples, and corrective actions.

4. Laboratory documents generally include the Laboratory QA Plan, shipping and log-in records, copies of analysis results, and correspondence relative to data reporting, sample deficiencies, and $\mathrm{QA} / \mathrm{QC}$ programs.

\section{DATA SECURITY}

Concentration data are either recorded on paper analysis forms or stored in computer files. Each type of documentation is somewhat vulnerable to potential data loss, and effective back-up measures are always needed. Concentration data recorded on paper analysis forms may be lost during their transmission to the customer. Copies of the analysis results should be made prior to transmission and retained by the laboratory for an indefinite period.

Concentration data compiled by computer may be lost due to power failure during analysis or by file damage during computer storage. Data loss during analysis is decreased by making temporary copies of log-in, weighing, and computation information at several stages in the analysis. Data loss in computer files is avoided by a daily back-up of file changes on magnetic tape. Computer system back-ups are routinely made at weekly intervals. Only the system administrator, district sediment specialist, and laboratory personnel have access rights to change analysis results in computer data files. 


\section{GLOSSARY}

The following definitions are given to provide complete descriptions of sediment and QA terms used in this document. Many of the terms are abstracted or modified from terminologies presented in publications such as the National Handbook of Recommended Methods for Water-Data Acquisition (1977) and the U.S. Geological Survey's TWRI series.

Accuracy: The extent to which the measured value of a quantity agrees with the accepted value for that quantity.

Bias: Systematic error that is manifested as a consistent positive or negative deviation from the known or true value. It differs from random error, which shows no such deviation.

Blank sample (solution): A solution that is free of the analyte(s) of interest. Such a solution would be used to develop specific types of blank samples as described below.

Field Blank - A blank solution that is subjected to all aspects of sample collection, field processing, preservation, transportation, and laboratory handling as an environmental sample.

Filter Blank - A blank solution that is filtered in the same manner and through the same filter apparatus used for an environmental sample.

Preservation Blank - A blank solution that is treated with the same preservatives used for an environmental sample.

Sampler Blank - A blank solution that is poured or pumped through the same field sampler used for the collection of an environmental sample.

Shelf (or Hold) Blank - A blank solution that is put in the same type of container/bottle used for an environmental sample and stored adjacent to an environmental sample in a storage area.

Splitter Blank - A blank solution that is mixed and separated using a field splitter in the same manner and through the same apparatus used for an environmental sample.

Trip Blank - A blank solution that is put in the same type of container/bottle used for an environmental sample and kept with the set of sample container/bottles both before and after sample collection.

Blind sample: A sample submitted for analysis whose composition is known to the submitter but unknown to the analyst.

Precision: The degree of similarity among independent measurements of the same quantity, without reference to the known or true value. It often is presented as the inverse of the standard deviation.

Quality: The totality of features and characteristics of a product or service that bear on its ability to satisfy stated or implied needs.

Quality Assurance (QA): All those planned or systematic actions necessary to provide adequate confidence that a product or service will satisfy given requirements for quality.

Quality Assurance Plan (QAP): A formal document describing the management policies, objectives, principles, organizational authority, responsibilities, accountability, and implementation plan of a group for ensuring quality in its products. 
Quality Control (QC): The operational techniques and the activities used to fulfill requirements of quality.

Reference material: A material or substance one or more properties of which are sufficiently well .established to be used for the assessment of a measurement method or for assigning values to materials.

Replicate samples: A group of samples, collected in a manner such that the samples are thought to be essentially identical in composition.

Replicate is the general case for which duplicate is the special case consisting of two samples or measurements.

Sample: A representative part of a larger whole; a finite part or subset of a statistical population.

Sediment:

(1) Particles derived from rocks or biological materials that have been transported by a fluid.

(2) Solid material (sludges) suspended in or settled from water (for additional information, see Bates and Jackson, 1987).

Sediment concentration $(\mathrm{mg} / \mathrm{L})$ : The ratio of the mass of dry sediment in a water-sediment mixture to the volume of the mixture. Sediment concentration is reported in milligrams per liter.

Sediment concentration (PPM): The ratio of the mass of dry sediment in a water-sediment mixture to the mass of the mixture multiplied by one million. Sediment concentration is expressed in parts per million.

Sediment sample: A quantity of water-sediment mixture or deposited sediment that is collected to characterize some property or properties of the sampled medium.

Specific conductance: A measure of the ability of a solution to conduct an electric current. Specific conductance is reported in microsiemens per centimeter at a temperature of $25^{\circ} \mathrm{C}$.

Standard: A material established for use as a rule or basis of comparison in measuring or judging capacity, quantity, content, extent, value, or quality.

Standard Method: An assemblage of techniques and procedures based on consensus, or other criteria, and often evaluated for its reliability by a collaborative testing and by having received organizational approval.

Suspended sediment: Sediment that is carried in suspension by the turbulent components of the fluid or by Brownian movement. 


\section{SELECTED REFERENCES}

Acceptable methods for the analysis and reporting of sediment data by the U.S. Geological Survey are given in the TWRI series; in internal technical memorandums of the Water Resources Division and the Division's Office of Surface Water and Office of Quality of Water, and other publications. Reference is made to the following publications:

\section{TECHNIQUES OF WATER-RESOURCES INVESTIGATIONS OF THE}

\section{UNITED STATES GEOLOGICAL SURVEY}

TWI 3-C2 Field methods for measurement of fluvial sediment by H.P. Guy and V.W. Norman, 1970,59 pages.

TWI 3-C3 Computation of fluvial-sediment discharge by George Porterfield, 1972, 66 pages.

TWI 5-A1 Methods for determination of organic substances in water and fluvial sediments by Marvin J. Fishman and L.C. Friedman, editors, 1985, 709 pages.

TWI 5-A6 Quality assurance practices for the chemical and biological analyses of water and fluvial sediments by L.C. Friedman and D.E. Erdmann, 1982, 181 pages.

TWI 5-C1 Laboratory theory and methods for sediment analysis by H.P. Guy, 1969, 58 pages.

\section{Additional References}

Alt, D.F., and Iseri, K.T., 1986, Water Resources Division publication guide--Volume I. Publication policy and text preparation: U.S. Geological Survey, 429 p.

American Society for Testing Materials, 1986, Test methods for turbidity of water (D1889-86):

American Society for Testing Materials, Philadelphia, Pa., 1986 Annual Book of ASTM

Standards.

1986, Practice for determining suspended-sediment concentration in water samples

(D2977-80): American Society for Testing Materials, 1986 Annual Book of ASTM Standards.

Bates, R.L. and Jackson, J.A., 1987, Glossary of geology: Alexandria, Va., American Geological Institute, 787 pages.

Edwards, T.K., and Glysson, G.D., 1988, Field methods for measurement of fluvial sediment: U.S. Geological Survey Open-File Report 86-531, 118 p.

Matthes, W.J., Sholar, C.J., and George, J.R., 1991, Quality-assurance plan for the analysis of fluvial sediment: U.S. Geological Survey Open-File Report 91-467.

Novak, C.E., 1985, WRD data reports preparation guide: U.S. Geological Survey, Water Resources Division Report, 119 p. 
U.S. Geological Survey, 1975, WATSTORE user's guide: U.S. Geological Survey Open-File Report 75-426.

1976, Preparation of water-resources data reports: U.S. Geological Survey Report.

_ 1977, National handbook of recommended methods for water-data acquisition: U.S. Geological Survey Report. 